\title{
TRANSFER \& CAPITALIZATION KNOWLEDGE MANAGEMENT SUPPORT FOR KNOWLEDGE APPLICATIONS DEVELOPMENT IN THE ENTERPRISE BUSINESS INTELLIGENCE
}

\author{
Rosu, S.M.; DragoI, G.; DraGHICI, A. \& GURAN, M.
}

Abstract: This paper analyses the knowledge transfer capitalization at the enterprise level and proposes a methodological models to support knowledge applications, based on the principal internal and external knowledge resources used during the product development process and business intelligence strategies elaboration. The validation of these methodologies will be carried out based on a practical application in a university and Romanian SME partnership. The aim of this project (university-SME's partnership) is to determine the new organization type for integrating in the virtual enterprise medium and to outsource shared resources of the university research centers to the industrial partners.

Key words: enterprise business intelligence, knowledge capitalization, knowledge management, knowledge applications.
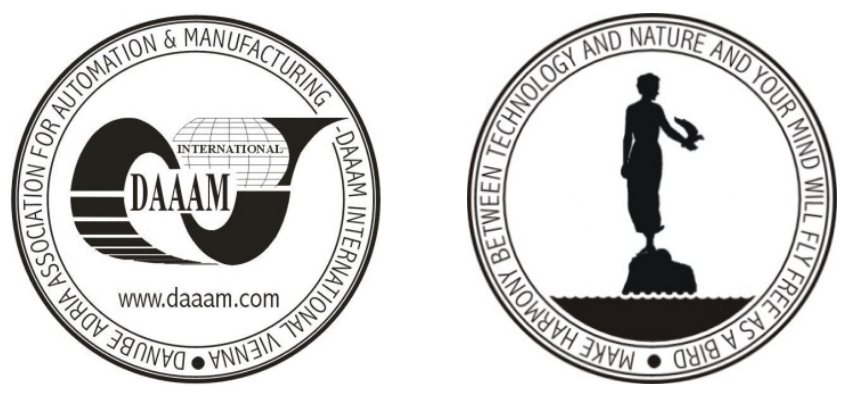

Authors' data: PhD. Student Rosu, S[ebastian] M[arius]*; Prof. Dragoi, G[eorge]**; Prof. Draghici, A[nca $]^{* * *}$, Prof. Guran, M[arius]**, *Special Telecommunications Service, Bld. Unirii, Bl. 37A, Et. 1, Ap. 7, 120237, Buzau, RO, ** University Politehnica of Bucharest, ILS Department, UPB-PREMINV Research Centre, 313, Splaiul Independentei, Sector 6, 060042, Bucharest, RO, ***Politehnica University of Timisoara, Str. Salciei 1 sc. B ap. 10, 300342, Timisoara, RO, sebastianrosu@stsnet.ro, gdragoi@mix.mmi.pub.ro, adraghici@eng.upt.ro,mguran@mix.mmi.pub.ro

This Publication has to be referred as: Rosu, S[ebastian] M[arius]; Dragoi, G[eorge]; Draghici, A[nca] \& Guran, M[arius] (2008). Transfer \& Capitalization Knowledge Management Support for Knowledge Applications Development in the Enterprise Business Intelligence, Chapter 57 in DAAAM International Scientific Book 2008, pp. 673-684, B. Katalinic (Ed.), Published by DAAAM International, ISBN 978-3-90150966-7, ISSN 1726-9687, Vienna, Austria

DOI: $10.2507 /$ daaam.scibook.2008.57 